\title{
9. Information Technology and New Media as Tools of Engagement
}

\author{
Martin Stewart-Weeks
}

What I intend to do in this chapter is briefly outline how we are starting to reshape and recast our conversations with citizens by using new technologies, and how this process is not only getting richer by the moment, but is often being driven not from within but from outside of the government.

First though, allow me to provide some background context. The head of the Department of Prime Minister and Cabinet Terry Moran said recently that, 'our processes should allow the community to provide input throughout the policy and service delivery process. Information technology can play a crucial role in facilitating communication between citizens and the government'. But I don't think we can understand the significance of what's going on in the conversation about new technology and what it's doing to the citizen-government relationship until we have a conversation about why. Why is this significant and what actually are these new techniques and these new platforms trying to achieve? What might they be driving or accelerating?

Distributed networking, the core architecture of the Internet, was essentially dreamt up in the 1960s when the big question in America was of maintaining the national communication system when Russia attacked (because, of course, we knew they certainly would). A distributing network was devised because, even if one of the communication nodes was brought down, the distributing network could still keep itself alive.

These are not suitable analogies, I think, for the world of government. Generally speaking, we have oscillated between these two systems - centralised and distributed. And generally speaking, we are learning how to operate in a distributing network - a process explored by Don Kettl (Chapter 3). And, while the early days of networking were all about control, our focus has now shifted to one of building resilience.

That is, essentially, what I would describe as the art and practice of connectedness: the notion that assets, culture and capability factors are having a fundamental impact on how we pull the two big levers that we've got available to us innovation and productivity - to do better things and to do things better. Resilience, in my opinion, is about bouncing back from risk and from the mad, chaotic world we live in, all the while bouncing forward. How do we start to build societies that are more resilient in a proactive sense? 
This sense of connectedness is very important. Nor is it the same as connectivity. Connectedness is about a culture of openness, sharing and co-creating; it's the art and practice of connectedness on which we need to focus.

My third observation is based on the work of business strategy consultant John Hagel who, with his team, have done some of the best thinking and writing about the information revolution. He talks about the increasing power of 'pull' in an environment that was once dominated by 'push' (the world of big governments and big corporations). At Cisco, we design and manufacture products, and then we get marketing people to go out and make you want the products. This is a scenario dominated by 'push'. Hagel argues that this oncedominant approach is gradually ceding to a world of 'pull', where people can use and get information, resources, insights, assets when and how they need them to suit their own needs.

Essentially, Hagel believes we are in a complete transformational refit process, including the underlying infrastructure (e.g., the National Broadband Network), the associated knowledge flows that they enable, and the traditional institutions of governments and markets. Of course, transforming the traditional institutions - their longstanding beliefs and mindsets is the hardest part of the refits process and I think we can learn some valuable lessons as to how to best do this in Kettl's chapter.

We are having richer and more meaningful conversations with citizens who are increasingly learning to live in the world of pull and are increasingly frustrated by the world of push. Much of this frustration with government is at least partially a function of the slow speed with which government is coming to understand that shift and acting accordingly. If you keep pushing at people who want to pull on their own terms, you're going to make them dissatisfied and unhappy.

Consider the recent work of Canadian Jocelyne Bourgon, a former senior public servant, in collaboration with the Australia and New Zealand School of Government (ANZSOG) and the Australian Public Service Commission. Called 'the New Synthesis', Bourgon is essentially trying to reinvent the business model for public administration in the twenty-first century. Her view is that public administration is no longer simply about compliance and performance. It is being transfomed into an area in which public servants and governments work to build resilience and anticipate emergent issues.

Another point is that we are living in a world where we are learning the power of the 'edge' (being 'out there' ahead of the pack). A few years ago a report written for the US Department of Defence asked: how do we turn the US 
defence machine into an 'edge organisation' and not a central organisation? ${ }^{1}$ This is an interesting and somewhat ambitious aim. Edge organisations have a fundamentally different power topology from traditional organisations, as is clear from the contributions to this volume.

It is also a thread in many of the following examples. Consider firstly, that in late 2011 the ACT Government held its first Twitter cabinet meeting. It was an interesting experiment that resulted in close to 700 tweets being made over one hour, and 170,000 followers of the related hashtag in the same amount of time - that's almost half the population of the ACT!

The 'conversations' that emerged from this experiment were impressive. Topics they covered included transport, planning, human rights and gay marriage. Some questions were answered on the spot and some ministers provided impressive answers within the 140-character parameters of Twitter, and they often included a link. Other ministers responded along the lines of: 'Thanks for the question. We'll get back to you.' Such potentially unhelpful responses made the success of the experiment ambiguous. My favourite tweet, appearing at the end of the session, ran: 'What just happened?' I thought: 'Yep, that's pretty much the right question.'

Another example of an Australian institution making brilliant use of social media came during the 2011 Queensland floods, when the state's police force embraced Facebook as a medium for spreading emergency messages. It was an innovation on the run: major flooding and intense cyclones meant that there was no time for the police force to seek the relevant permissions through their regular channels. Faced with these challenges, the risk of using Facebook as a way of keeping people informed about developments - and to harness their views - was successful.

There have been other examples of innovative use of social media around the world. Ushahidi is a web-based platform that was initially developed to alert people to the outbreak of political violence in the aftermath of Kenya's disputed 2007 presidential election. Using open source technology on a simple website, it allowed citizens to provide geographical information about where violence was occurring. The platform has since been picked up in cities throughout the world for other purposes. In Atlanta, for example, it is used for mapping crime.

The North Atlantic Treaty Organisation (NATO) has also pioneered the use of social media. Last year, the organisation held a 'policy jam' that involved 4000 participants, 10,000 log-ins, 124 countries, five days, 10 streams, 26 online hosts and 75 facilitators. This last figure is a reminder that none of this spontaneous

1 M.S. Vassiliou, 'The Evolution Towards Decentralization C2', Institute for Defense Analyses, Washington, January 2010. 
combustion happens without a complex choreography and preparation. That said, I suspect NATO has never had such a casual conversation about policy. Participants in the jam produced many ideas and suggestions and made particular recommendations, although it is not yet known how NATO has developed them.

In the United States, Cisco are working in a number of cities on the use of video technologies that can be uploaded to shared websites in a bid to reduce crime and violence amongst young people. It's about storytelling and capturing those stories on videos and uploading them onto a website where they can be shared and where they can spark conversation. Often, when we talk about greater engagement between citizens and government, we talk about the notion of citizens giving us feedback about our services. What I am talking about is different and it involves making the citizens the service and asking what we can do to enable that.

A point to make here, though, is that citizen engagement through technology is more about policy-makers waiting to hear from citizens. But, it is often more valuable for policy-making agencies to transfer information, which the public can then use, in sometimes unpredictable ways. It is doubtful that this is happening at the moment. Are the current efforts at citizen engagement creating services that people want, and delivering more effectively than any other model?

There are many companies now using complex online consultation mechanisms as a way of opening up the channels of dialogue between policy-making institutions and citizens. But it is not without risks. The Melbourne-based community forum Bang the Table gained notoriety in Victoria for releasing some sensitive information too early in 2010. This experience highlighted the potential risks when you start making the systems more porous, but nonetheless, it has been successful in most instances.

The United Kingdom, under the Conservative-Liberal Democrat coalition elected in 2010, is also busy opening up its channels for citizen engagement. In a bid to seek citizen input, the UK national archives are putting much of the material that they hold into the public sphere. In Australia, BetaWorks is a website that gives Australian Bureau of Statistics designers a place to showcase what they're working on, in order to gain feedback from the public and make sure that it meets the needs of the public. In many cases, I think, the jury is still out as to how effective such approaches are, but again, improving the dialogue between policy-makers and citizens requires experimentation with new methods.

In the United States, Facebook users now have access to 'a citizen request tracker'. An updated version of the 'rat-catching model' that Kettl references in an earlier chapter, it allows users to report city issues (potholes, code violations, 
animal matters etc) and then allow them to track their requests and see whether action was taken. The geographic location of each report or sighting is shown publically, allowing other users to respond.

A surprising pioneer in new citizen engagement methods has been the US Patent and Trademark Office (USPTO). Recognising that it has a shortage of expertise in key areas within the organisation, the USPTO has started to use social networking technologies to attract a wider audience of experts who can help them assess patent applications. As somebody once remarked, the trouble with our organisation is that most of the bright people we really need don't work for us, so the question is how do you find them, how do you harness them and how do you connect to them?

To do this, it is important to redefine the notion of expertise. In the commercial world, as well as in government and in the worlds of research and development, large corporations are beginning to realise that the kind of expertise they want tests the parameters under which they operate. This is an important point because for governments, there are lessons to be learned about where and how to listen to people who don't fit within those particular parameters, but who have genuine expertise to offer.

This is a challenge for governments because asking people to adhere to proscriptive guidelines can't possibly work anymore. By using social media, or other new forms of technology, citizens will find 110 different ways to make sure that governments, or somebody, does listen - in ways which can seem counterintuitive and even dysfunctional.

My penultimate example comes from the Australian Centre for Social Innovation's annual 'challenge'. A recent winner was a website aiming to increase community interest about the issue of binge drinking amongst younger people. Called 'Hello Sunday Morning', the website relies on people to voluntarily make claims and commitments about the way they're going to manage and improve their drinking habits. They are also encouraged to share their drinking problems with other members of the online community. Hello Sunday Morning is a way of engaging citizens on the basis that they are the service, as opposed to somebody providing them with a service. Technology can make that both appealing and convenient. This approach is also growing rapidly.

Additionally, if you visit the Australian Government Information Management Office website you will find several examples of people who are beginning to use social technology and technology more broadly in different and experimental ways. All agencies — tax agencies, human service agencies, and others - are 
trying to reshape the conversation between citizens and government. I mention this as a way of highlighting that there are lots of places now that are beginning to aggregate this information.

I will finish by outlining what I think may come from all of this. My observation is that the big human interaction sectors of the economy, such as the worlds of banking, airlines, retail and other big commercial arenas, are having to learn the important lesson that, although our social networks are not omniscient, they generally know more about things than we do. The tables have turned.

My experience is that, generally speaking, the government and the public sector work from almost exactly the opposite presupposition - that they know more than the network does, and only occasionally will they let the network in (by running a survey, for example). This is shortsighted and unwise. We are talking about a massive new invitation to engage in a myriad of different ways, we must embrace this offer.

We are talking about a world in which power, control and authority are being devolved and dispersed. Accepting and adapting to this is a challenge for those organisations that are accustomed to having all of those things. This is not, however, an either/or world, nor is it necessarily a case of 'in with the new, out with the old'. Just because everyone's on Facebook and Twitter and just because the five biggest airlines in the United States now have two-and-a-half million Facebook 'fans', does not mean we should totally ignore our old approaches. Social networking sites have provided US airlines with the biggest customer sample those companies have ever had, yet this doesn't mean the predictable institutional mechanisms involved in running an airline suddenly just disappear.

The problem is that the world that is being unleashed by some of the technology that I have sketched is very different to the one we have grown accustomed to over the past 20 or 30 years. What we must realise, however, is that the Internet and its attendant social networking technologies provide coherence, scale and accountability, but in different forms to before. It is now incumbent upon the public service to understand and adapt to these new forms.

\section{References}

Bourgon, J. 2011. A New Synthesis of Public Administration: Serving in the 21st century. Kingston, Ontario: McGill-Queen's University Press.

Hagel, J., Brown, J.S. and Davidson, L., 2010, The Power of Pull: How small moves, smartly made, can set big things in motion. Basic Books. 